(2) Open Access Full Text Article

ORIGINALRESEARCH

\title{
Intention to Screen for Cervical Cancer Among Child Bearing Age Women in Bahir Dar City, North-West Ethiopia: Using Theory of Planned Behavior
}

\section{Wallelign Alemnew Getu Debalkie (D) \\ Telake Azale}

Department of Health Education \& Behavioral Sciences, Institute of Public Health, College of Medicine and Health Sciences, University of Gondar, Gondar, Ethiopia
Correspondence: Wallelign Alemnew Tel +25I 942331608

Email wallelignaleminew@gmail.com
This article was published in the following Dove Press journal:

International Journal of Women's Health

Background: Cervical cancer screening is consistently effective in reducing the incidence and mortality rates associated with cervical cancer. However, very few women have received cervical cancer screening in the developing countries including Ethiopia. Therefore, this study aims to assess cervical cancer screening intention and its predictors among child bearing age women in Bahir Dar city, North-West Ethiopia.

Methods: A community-based cross-sectional study was conducted among 832 child bearing age women using a multistage sampling technique between March and April, 2018. Data were collected using a structured questionnaire through face-to-face interviews. Data were entered and analyzed using EpiData and SPSS version 20.0, respectively. Simple and multiple linear regression analyses were done to identify predictors of intention, and $P<0.05$ was used as a cutoff to determine statistical significance at multiple regressions.

Results: Eight hundred and thirty-two (98\%) respondents participated in this study. The mean age of the participants was $31 \pm$ SD 7.23 years, ranging from 18-49 years. The majority $(61.4 \%)$ of the participants were married. The mean score of intention to receive cervical cancer screening was $10.5 \pm 2.03$, with a minimum and maximum sore of 5 and 15 , respectively. Four hundred and fifty-eight $(55 \%)(95 \% \mathrm{CI}=51.7-58.3)$ respondents scored above the mean score. Direct perceived behavioral control $(\beta=0.19, P<0.001)$, direct subjective norm $(\beta=0.06, P<0.001)$, direct attitude $(\beta=0.15, P<0.001)$, and past screening experience $(\beta=0.64$, $P<0.001)$ were found to be significant predictors of intention.

Conclusion: Perceived behavioral control, attitude towards the behavior, subjective norm, and past screening experience were the predictors of intention, and perceived behavioral control was the strongest predictor. Hence, behavioral change communication interventions are crucial to change their attitude and empower them to evaluate their control and normative beliefs.

Keywords: cervical cancer, human papilloma virus, theory of planned behavior, Ethiopia

\section{Introduction}

Cervical cancer is a type of cancer which is found in the lower reproductive system of females, and is caused by human papilloma virus. Seventy percent $(70 \%)$ of all cervical cancer cases throughout the world are caused by only two types of human papillomavirus (HPV); HPV-16 and HPV-18. ${ }^{1,2}$ Nearlyall sexually active individuals will be infected with HPV once in their lives, and some may be infected frequently. ${ }^{2}$ Worldwide, around 528,000 new cases were diagnosed, and over 
280,000 women died from cervical cancer. Among these, around $90 \%$ of new cases and deaths occur in the developing world, including Sub-Saharan Africa. ${ }^{3-5}$ Especially Eastern African countries still have a high incidence and mortality. 6,7 Evidence shows that, in Ethiopia, 29.43 million women aged 15 and older are at risk of developing cervical cancer. Current estimates indicate that every year 7,095 women are diagnosed with cervical cancer, and 4,732 die from the disease per year. ${ }^{8}$ Cervical cancer ranks as the second most frequent cancer among women in Ethiopia and the leading cause of cancer related deaths. ${ }^{9}$ Studies revealed that the age-adjusted incidence rate of cervical cancer in Ethiopia is 35.9 per 100,000 patients, with 7,619 new cases and 6,081 deaths every year. ${ }^{10}$ The distribution of the problem across different regions in Ethiopia between 1997-2012 was $32.98 \%, 30.15 \%$, and $19.72 \%$ in Addis Ababa, Oromia, and Amhara, respectively. ${ }^{11,12}$ Cervical cancer can be prevented by an effective cervical cancer screening test, ie, detecting precursors before a woman develops any signs and symptoms, and it makes it easy to treat or cure if the cancer is found timely. ${ }^{13-15}$ Studies show that only $5 \%$ of women from the developing world receive cervical cancer screening, ${ }^{6,16}$ which is very low compared to the $84 \%$ in the developed world. ${ }^{17}$ Although receiving the screening test plays an important role in preventing cervical cancer, only $1.6 \%$ and $0.4 \%$ of women received the screening service in urban and rural Ethiopia, respectively. ${ }^{18}$ According to the theory of planned behavior, behavioral intention is the best predictor of a certain behavior which is determined by attitude towards the behavior, subjective norms associated with the behavior, and perceived behavioral control over the behavior. ${ }^{19}$ Currently there is a dearth of research on cervical cancer screening intention and its predictors among child bearing age women in the study area using behavioral models, ie, theory of planned behavior. Therefore, the aim of this study is to assess intention and its predictors among child bearing age women in Bahir Dar city, North West Ethiopia.

\section{Methods}

\section{Study Design and Setting}

A community-based cross-sectional study design was conducted from March to April, 2018. The study was conducted in Bahir Dar city administration, the capital city of Amhara National Regional State. The city is elevated
$1,840 \mathrm{~m}$ above sea level and located in North West Ethiopia, $565 \mathrm{~km}$ from Addis Ababa, the capital of Ethiopia. Bahir Dar has nine administrative sub cities, which contains 17 Kebeles. According to Bahir Dar city administration health office, the estimated total population was 549,429 by 2017 , and the estimated number of reproductive age women was 164,829 , which accounts for $30 \%$ of the total population. Concerning the health infrastructure, the city has two government-owned hospitals and ten health centers. In addition, the town has two private hospitals, seven higher clinics, ten medium clinics, five special junior clinics, and three NGO clinics.

\section{Source and Study Population}

Women whose age ranging from 18-49 years were the source population for this study and women who had the chance of being randomly selected from the source population at a household level were the study population.

\section{Inclusion and Exclusion Criteria}

Women who were living in the study area for at least 6 months and aged 18-49 years were included, whereas women who were already screened and diagnosed for cervical cancer and who have had total hysterectomy were excluded in the study.

\section{Sample Size Determination and Sampling Procedure}

The sample size was calculated using a single population proportion formula considering $(P=0.5) 95 \%$ confidence interval, $5 \%$ margin of error, and $10 \%$ for non-response during data collection and design effect $=2$. Hence, the final sample size was 845 . Multistage sampling technique was used to select the study participants. In the first step three sub-cities ( $30 \%$ of the total area) were randomly selected from among nine sub-cities by using lottery method. Then a total of 845 households were selected using a systematic random sampling method. In this process samples were proportionally allocated to each of the selected sub-cities. To calculate the sampling fraction, total numbers of households were obtained from the respective administrative bodies. The initial interviewed household was randomly selected by lottery method, and the next were selected by every Kth house which is every " 16 th". When two or more individuals who fulfilled the inclusion criteria were found, only one individual who fulfilled the inclusion criteria was 
interviewed from the household in which lottery method was applied.

\section{Data Collection and Analysis}

The questionnaire was adapted from different reviewed literature ${ }^{13,20,21,22,23}$ and modified based on the results of the elicitation study. It was developed in English and translated into the local language "Amharic". Data were collected using a pretested and structured questionnaire through face-to-face interview with data collectors. Six female diploma nurses were trained for 1 day and each assigned for data collection, and one BSc Nurse participated in the training as a supervisor. The training included the objectives of the study, data collection techniques, contents of the questionnaire, procedures, and issues related to confidentiality. EpiData version 3.02.4 and Statistical Package for Social Sciences (SPSS) version 20.0 were used for data entry and analysis, respectively. Simple and multiple linear regression analyses were done to identify predictors of intention for cervical cancer screening.

\section{Measurements and Scoring}

A total of 12 items were used to measure the direct constructs of the TPB. Direct attitude; overall evaluation of cervical cancer screening as being positive or negative. It was measured using four semantic scale type items with five scales, a reliability test of $\dot{\alpha}=0.67$. Higher score indicates stronger attitude towards receiving cervical cancer screening. Direct subjective norm; perception of the social pressure to receive cervical cancer screening service or not. It was assessed using four Likert type items having a reliability test of $\dot{\alpha}=0.75$, for example "Most people who are important to me will think that I should receive cervical cancer screening", and a higher score indicates subjective norms encouraging undergoing cervical cancer screening. Direct perceived behavioral control; the perceived ability of an individual to control factors which influences cervical cancer screening. It was assessed using four semantic scale type items having a reliability of $\alpha=0.70$, for example, "it is difficult for me to receive cervical cancer screening", and a higher score indicated controlling more perceived behavior to undergo cervical cancer screening. Similarly, indirect TPB model variables were measured by Likert type items having five scales (ie, (strongly disagree, agree, neutral, agree, and strongly agree).
And the values were calculated by using the product sum of the respective construct. Indirect attitude; is composed of behavioral belief, ie, one's belief about the likely outcome of uptaking cervical cancer screening, and outcome evaluation, ie, one's judgmental evaluation of the outcome of the behavior. It was measured by 14 Likert type items, seven items from behavioral belief and seven from outcome evaluation. Indirect subjective norm; It is a combination of normative belief, ie, one's belief about what significant others think that he/she should or should not uptake cervical cancer screening or behavior in question and one's readiness to perform the behavior on the way of what significant others want him/her to do. It was measured using eight Likert type items, four items from normative belief, and four from motivation to comply. Indirect perceived behavioral control; also a combination of once control belief, ie, belief about the facilitators/barriers to cervical cancer screening uptake and power to control those control beliefs. Finally it was measured using 10 Likert type items, five items from control belief and five from power of control. Intention was assessed using three Likert type items with a reliability test of Cronbach's alpha $(\dot{\alpha}=0.88)$. Eleven composite score of knowledge items were used to measure the level of knowledge of the respondents regarding vulnerable groups, risk factors, signs and symptoms, and prevention methods of cervical cancer. For each knowledge, item scores were summed up to get over all knowledge scores, individuals correctly answered the item given a value of " 1 " and for those answered incorrectly valued "0", and then mean and standard deviation were calculated (Table 1).

\section{Results Sociodemographic Characteristics}

A total of 832 respondents participated in this study, making a response rate of $98 \%$. The participants' ages ranged from 18-48 years. The mean age of the study participants was 31.39 years with a standard deviation of 7.23. Most of the respondents were Amhara (787, 94.6\%), married (511, 61.4\%), and Orthodox Christian $(671,80.6 \%)$. The majority of the respondents (308, $25.5 \%)$ were private employees, whereas 212 (24.4\%) were government employees (Table 2). 
Table I Summary of Direct and Indirect Measures of Theory of Planned Behavior Variables

\begin{tabular}{|c|c|c|c|c|c|}
\hline & $\begin{array}{l}\text { TPB } \\
\text { Constructs }\end{array}$ & Items & Scale & Scoring & Outcome \\
\hline 1 & Attitude & 4 & SDs & $\sum_{i=1}^{4} A i$ & DA score \\
\hline 2. & $\begin{array}{l}\text { Subjective } \\
\text { norms }\end{array}$ & 4 & SDs & $\sum_{i=1}^{4} S N i$ & DSN score \\
\hline 3 & $\begin{array}{l}\text { Perceived } \\
\text { behavioral } \\
\text { control }\end{array}$ & 4 & SDs & $\sum_{i=1}^{4} P B C i$ & DPBC score \\
\hline 4 & Intention & 3 & Likert & $\sum_{i=1}^{3} I N i$ & IN score \\
\hline \multirow[t]{2}{*}{5} & $\begin{array}{l}\text { Behavioral } \\
\text { belief }\end{array}$ & 7 & \multirow[t]{2}{*}{ Likert } & \multirow[t]{2}{*}{$\sum_{i=1}^{7}\left(b b_{i} o e_{i}\right)$} & \multirow[t]{2}{*}{$\begin{array}{l}\text { Indirect } \\
\text { attitude/IA./ }\end{array}$} \\
\hline & $\begin{array}{l}\text { Outcome } \\
\text { evaluation }\end{array}$ & 7 & & & \\
\hline \multirow[t]{2}{*}{6} & $\begin{array}{l}\text { Normative } \\
\text { belief }\end{array}$ & 4 & \multirow[t]{2}{*}{ Likert } & \multirow[t]{2}{*}{$\sum_{i=1}^{4}\left(n b_{i} m c_{i}\right)$} & \multirow{2}{*}{$\begin{array}{l}\text { Indirect } \\
\text { subjective } \\
\text { norm/ISN./ }\end{array}$} \\
\hline & $\begin{array}{l}\text { Motivation } \\
\text { to comply }\end{array}$ & 4 & & & \\
\hline \multirow[t]{2}{*}{7} & $\begin{array}{l}\text { Control } \\
\text { belief }\end{array}$ & 5 & \multirow[t]{2}{*}{ Likert } & \multirow[t]{2}{*}{$\sum_{i=1}^{5}\left(c b_{i} p c_{i}\right)$} & \multirow{2}{*}{$\begin{array}{l}\text { Indirect } \\
\text { perceived } \\
\text { behavioral } \\
\text { control/IPBC }\end{array}$} \\
\hline & $\begin{array}{l}\text { Power of } \\
\text { control }\end{array}$ & 5 & & & \\
\hline
\end{tabular}

Abbreviations: DA, direct attitude; DSN, direct subjective norm; DPBC, direct perceived behavioral control; IN, intention; SDs, semantic differentials.

\section{Past Cervical Cancer Screening} Experience and Knowledge of the Respondents Regarding Cervical Cancer Screening

Of all the respondents, only 120 (14.4\%) of them had been screened for cervical cancer before the survey. Some of the reasons mentioned by the respondents why they did not receive the screening service included fear of pain $(38 \%)$, feeling embarrassed from the procedure $(35 \%)$, fears of a positive screening result (40.6\%), cost of the service $(63.5 \%)$, and being busy with social activities (54\%). The knowledge of participants about cervical cancer screening was estimated using mean score. Hence, the mean and standard deviation of knowledge score was $4.43 \pm 1.99$,
Table 2 Sociodemographic Characteristics Results of Child Bearing Age Women in Bahirdar City, 2018

\begin{tabular}{|c|c|c|}
\hline Characteristics & Category & Frequency \\
\hline Marital status & $\begin{array}{l}\text { Married } \\
\text { Single } \\
\text { Divorced } \\
\text { Widowed }\end{array}$ & $\begin{array}{l}5 I I(6 I .4) \\
230(27.6) \\
64(7.7) \\
27(3.2)\end{array}$ \\
\hline Religion & $\begin{array}{l}\text { Orthodox Christian } \\
\text { Muslim } \\
\text { Protestant } \\
\text { Catholic }\end{array}$ & $\begin{array}{l}671(80.6) \\
88(10.6) \\
60(7.2) \\
13(1.6)\end{array}$ \\
\hline Ethnicity & $\begin{array}{l}\text { Amhara } \\
\text { Oromo } \\
\text { Tigre }\end{array}$ & $\begin{array}{l}787(94.6) \\
25(3.0) \\
20(2.4)\end{array}$ \\
\hline Respondent' age & $\begin{array}{l}18-24 \\
25-29 \\
30-34 \\
35-49 \text { years }\end{array}$ & $\begin{array}{l}143(\mid 7.2) \\
228(27.4) \\
I 76(2 \mid .2) \\
285(34.3)\end{array}$ \\
\hline $\begin{array}{l}\text { Respondents' educational } \\
\text { level }\end{array}$ & $\begin{array}{l}\text { I-8(primary) } \\
9-12(\text { secondary) } \\
\text { above } 12^{+} \text {(tertiary) }\end{array}$ & $\begin{array}{l}263(31.6) \\
237(28.5) \\
332(39.9)\end{array}$ \\
\hline Respondents' occupation & $\begin{array}{l}\text { Government } \\
\text { employee } \\
\text { Private } \\
\text { Unemployed } \\
\text { Housewife } \\
\text { Student }\end{array}$ & $\begin{array}{l}212(25.5) \\
308(37.0) \\
31(3.7) \\
203(24.4) \\
78(9.4)\end{array}$ \\
\hline Partners' occupation & $\begin{array}{l}\text { Government } \\
\text { employee } \\
\text { Private } \\
\text { Unemployed }\end{array}$ & $\begin{array}{l}211(25.4) \\
294(35.3) \\
6(0.7)\end{array}$ \\
\hline Partners' educational level & $\begin{array}{l}\text { I-8 (primary) } \\
\text { Grade 9-12 } \\
\text { Tertiary }(12+)\end{array}$ & $\begin{array}{l}137(16.5) \\
133(16.0) \\
24 \mid(28.8)\end{array}$ \\
\hline Monthly income & $\begin{array}{l}<900 \\
900-1,600 \\
1,600-2,700 \\
>2,700\end{array}$ & $\begin{array}{l}68(8.2) \\
193(23.2) \\
237(28.5) \\
334(40.1)\end{array}$ \\
\hline
\end{tabular}

and $60.6 \%$ of the respondents scored above the mean score.

\section{Magnitude of Intention}

In this study, more than half of the respondents $(458,55 \%$; 95\% CI $=51.7-58.3)$ scored above the mean score. The actual minimum and maximum scores were 5 and 15 , respectively. The mean intention score was $10.5 \pm 2.03$. 


\section{Pearson Correlation Analysis of Direct and Indirect Determinants of TPB}

There was a positive correlation between direct attitude with indirect attitude $(\mathrm{r}=0.51)$, direct subjective norm with indirect subjective norm $(\mathrm{r}=0.61)$, and direct perceived behavioral control with indirect perceived behavioral control $(\mathrm{r}=0.20)$ (Table 3).

\section{Simple and Multiple Linear Regression Analysis}

Simple linear regression analysis was done to assess the association between all independent variables with intention after checking normality. All variables at a $P$-value less than 0.20 in simple linear regression were fitted to multiple linear regressions and identified the independent predictor of intention. Unstandardized coefficients and $\mathrm{R}^{2}$ values were used to interpret the effects and variability in the dependent variable, respectively. A significant independent predictor was declared at $95 \%$ confidence interval and a $P$-value less than 0.05 (Table 4)

\section{Discussion}

The study examined the utility of TPB in predicting cervical cancer screening intention among child bearing age women in Bahir Dar city, North West Ethiopia. We used a linear regression analysis model to identify the predictors of cervical cancer screening intention. Using this model in this study has numerous advantageous or importances including; it shows the strength of the association between the outcome (dependent variable) and predictor (independent), used to identify the strongest variable (predictor) and helps in analyzing the extent of change in the independent variable by one "unit" would affect the dependent variable. On the other hand the model has its own limitations like not informative for policy-makers or decisionmakers. ${ }^{24,25}$

Table 3 Correlation Analysis of Direct and Indirect Constructs of Theory of Planned Behavior

\begin{tabular}{|l|l|l|l|l|l|l|l|}
\hline & Mean (SD) & I & $\mathbf{2}$ & $\mathbf{3}$ & $\mathbf{4}$ & $\mathbf{5}$ & $\mathbf{6}$ \\
\hline I. Direct Att. & $15.97(2.1 \mathrm{I})$ & $\mathrm{I}$ & & & & & \\
2. In direct Att. & $123.97(33.34)$ & $5 \mathrm{I}$ & $\mathrm{I}$ & & & & \\
3. Direct PBC & $15.84(2.90)$ & 44 & 64 & 1 & & & \\
4. Indirect PBC & $47(25.15)$ & 18 & 17 & 20 & $\mathrm{I}$ & & \\
5. Direct SN & $17.23(4.26)$ & 36 & 57 & 58 & 14 & $\mathrm{I}$ & \\
6. Indirect SN & $48.50(19.39)$ & 33 & 59 & 45 & 16 & $6 \mathrm{I}$ & 1 \\
\hline
\end{tabular}

Note: Correlation is significant at 0.05 (2 tailed).
In this study, direct perceived behavioral control, direct attitude, direct subjective norm, and past screening experience were the predictors of intention to receive cervical cancer screening among child bearing age women.

Direct perceived behavioral control was the strongest predictor of intention to receive cervical cancer screening. The finding is supported with studies conducted in southern Ethiopia and Latin-American using Theory of Planned Behavior which found that perceived behavioral control was positively strongly associated with intention to be screened for cervical cancer screening. ${ }^{26,27}$ However, perceived behavioral control was the least predictor in a study conducted in Jimma, Ethiopia. ${ }^{28}$ The difference may be due to the context where the study was conducted. This suggests that, considering those control factors are crucial in supporting women to receive cervical cancer screening. Women, who are able to control fear of pain during the procedure; feeling embarrassed and fear of being tested positive lead to increase their intention to screening. This is supported with Ajzen's theoretical assumptions which mean that the more individuals have a high degree of control over factors that facilitate or prevent them to receive cervical cancer screening; the greater will be their intention to receive cervical cancer screening. ${ }^{29}$

In this study direct attitude was the second strongest important predictor of intention to receive cervical cancer screening. The finding is in line with a study conducted in Amhara region, Ethiopia ${ }^{8}$ and a study conducted in western Iran which investigated that attitude was a predictor of intention for cervical cancer screening. ${ }^{30}$ This indicates that targeted IEC/BCC should be conducted to create favorable attitude towards cervical cancer screening. Those women who believe that receiving cervical cancer screening helps to detect the cancerous lesion at early stage and also helps to treat and cure the cancer at early stage were more likely to have had a favorable attitude and then more intended to receive cervical cancer screening.

The study also found that the subjective norm was the least significantly influenced cervical cancer screening intention. This finding is supported with research conducted in Singaporean women using the Theory of Planned Behavior, which found a high level of subjective norm significantly predicting cervical cancer screening intention. ${ }^{31}$ However, another study conducted in southern Ethiopia revealed that subjective norm was the second best predictor next to perceived behavioral control with intention to cervical cancer 
Table 4 Multiple Linear Regression Analysis Result on Cervical Cancer Screening Intention Among Childbearing Age Women in Bahirdar City, 2018

\begin{tabular}{|c|c|c|c|c|}
\hline Variables & Unstandardized $\beta$ & Standardized B & $95 \% \mathrm{Cl} \beta$ & \\
\hline & 3.70 & - & 2.14 & 5.25 \\
\hline Direct attitude & $0.15^{*}$ & 0.14 & 0.08 & 0.23 \\
\hline Direct SN & $0.06 *$ & 0.12 & 0.02 & 0.09 \\
\hline Direct PBC & $0.19 *$ & 0.28 & 0.14 & 0.25 \\
\hline \multicolumn{5}{|l|}{ Past screening experience } \\
\hline \multicolumn{5}{|l|}{ No (ref) } \\
\hline Yes & $0.64^{*}$ & 0.11 & 0.29 & 0.88 \\
\hline \multicolumn{5}{|l|}{ Monthly income } \\
\hline \multicolumn{5}{|l|}{$<900$ (ref) } \\
\hline $900-1,600$ & 0.32 & 0.06 & -0.19 & 0.83 \\
\hline $1,600-2,700$ & 0.37 & 0.08 & -0.14 & 0.88 \\
\hline$>2,700$ & 0.30 & 0.07 & -0.24 & 0.85 \\
\hline \multicolumn{5}{|l|}{ Marital status } \\
\hline \multicolumn{5}{|l|}{ Single (ref) } \\
\hline Married & 0.20 & 0.05 & -0.16 & 0.57 \\
\hline Divorced & 0.70 & 0.09 & 0.19 & 1.21 \\
\hline Widowed & 0.33 & 0.02 & -0.39 & 1.05 \\
\hline \multicolumn{5}{|l|}{ Respondents occupation } \\
\hline \multicolumn{5}{|l|}{ Unemployed (ref) } \\
\hline Government employee & -0.24 & -0.05 & -0.95 & 0.46 \\
\hline Private & -0.68 & -0.16 & -1.36 & -0.00 \\
\hline Housewife & -0.46 & -0.09 & -1.17 & 0.24 \\
\hline Student & -0.14 & -0.02 & -0.91 & 0.62 \\
\hline \multicolumn{5}{|l|}{ Husbands education } \\
\hline \multicolumn{5}{|c|}{ Unable to write and read (ref) } \\
\hline able to read and write & -0.09 & -0.00 & -1.35 & 1.16 \\
\hline secondary school & -0.02 & -0.00 & -1.12 & 1.06 \\
\hline tertiary & 0.02 & 0.00 & -1.06 & 1.11 \\
\hline primary school & -0.54 & -0.09 & -1.66 & 0.56 \\
\hline
\end{tabular}

Note: $* P<0.05$.

Abbreviation: ref, reference.

screening. ${ }^{27}$ The difference could be attributed to the context or the place/region where the behavior is performed and the study was conducted. This implies that significant others/ families, friends, relatives, and health professionals have a power to influence women's decision. Hence, interventions should focus on both the targeted population and significant others, those who have a power to influence others decisions, such as family members, friends, relatives, and healthcare providers as a whole to improve cervical cancer screening utilization.

Past cervical cancer screening experiences were another significant variable. Women having past cervical cancer screening experience were more intended to receive cervical cancer screening than those who had no previous experience. This finding was supported by research conducted in Latin-America ${ }^{19,26}$

\section{Conclusion}

In this study, attitude, subjective norm, perceived behavioral control, and past cervical cancer screening experience were the predictors of intention to receive cervical cancer screening service. Behavioral change communication interventions are important to change the women's attitude and empowerthem to evaluate their control and normative beliefs. Finally, this study has its own limitation that did not account for the actual behavior to be predicted based on the theory of planned behavior constructs which may show how much behavioral intention could be transformed into the actual behavior. 


\section{Recommendation}

A longitudinal study which incorporates screening behavior should be considered in the future to see how the behavioral intention transformed into the actual behavior.

\section{Abbreviations}

HPV, Human Papilloma Virus; TPB, Theory of Planned Behavior; WHO, World Health Organization; DA, Direct Attitude; DSN, Direct Subjective Norm; DPBC, Direct Perceived Behavioral Control; IN, Intention; IA, Indirect Attitude; ISN, Indirect Subjective Norm; IPBC, Indirect Perceived Behavioral Control; NGO, Non-Governmental Organization.

\section{Data Sharing Statement}

The datasets used and/or analyzed during the current study are available from the corresponding author on reasonable request.

\section{Ethics and Consent}

Ethical clearance was obtained from Ethical Review Committee of Institute of Public Health, Collage of Medicine and Health Sciences, University of Gondar. All the study participants were fully informed about the purpose of the study, their right to refuse, assurance of confidentiality and privacy during interview. Informed, voluntary and written consent was obtained from each participant before data collection. Strict confidentiality was maintained through anonymous recording and coding of questionnaire.

\section{Consent for Publication}

Not applicable.

\section{Acknowledgment}

We would like to thank the academic staff of the Department of Health Education and Behavioral Science, Institute of Public Health, University of Gondar for their generosity, support, and cooperation. Finally, we would like to acknowledge the data collectors, supervisors, and participants for their unreserved cooperation.

\section{Author Contributions}

All authors made substantial contributions to the conception and design, acquisition of data, or analysis and interpretation of data; took part in drafting the article or revising it critically for important intellectual content; agreed to submit to the current journal; gave final approval of the version to be published; and agree to be accountable for all aspects of the work.

\section{Funding}

The study was funded for academic purpose by grants from University of Gondar, College of Medicine and Health Sciences, Institute of public Health. The funders had no impact on design, collection, management, analysis, and interpretation of the data; and preparation, review, or approval of the manuscript.

\section{Disclosure}

The authors declare that they have no conflicts of interest.

\section{References}

1. Ruddies F, Gizaw M, Teka B, et al. Cervical cancer screening in rural Ethiopia: a cross-sectional knowledge, attitude and practice study. BMC Cancer. 2020;20(1):1-10. doi:10.1186/s12885-020-07060-4

2. Bayu H, Berhe Y, Mulat A, Alemu A. Cervical cancer screening service uptake and associated factors among age eligible women in Mekelle Zone, Northern Ethiopia, 2015: a community based study using health belief model. PLoS One. 2016;11(3):e0149908.

3. Scored Research A, \& Design By Africa Health, Human \& Social Development Information Service (Afri-Devi.Info) \& Africa Coalition On Maternal Newborn \& Child Health. Integrated Africa Cancer Fact Sheet Focusing on cervical cancer+ Girls and Women Health /Sexual and Reproductive Health, HIV and Maternal Health. 2014.

4. WHO.cervical cancer prevention and control saves lives in the Republic of Korea. 2018; Available from: https://www.who.int/ news-room/feature-stories/detail/cervical-cancer-prevention-and-con trol-saves-lives-in-the-republic-of-korea.

5. Ethiopia FMoH. National Cervical Cancer Prevention Training Package Participants Manual Ethiopia: Ministry of Health; 2015.

6. Kangmennaang J, Thogarapalli N, Mkandawire P, Luginaah I. Investigating the disparities in cervical cancer screening among Namibian women. Gynecol Oncol. 2015;138(2):411-416. doi:10.1016/j.ygyno.2015.05.036

7. Ntekim A, Campbell O, Rothenbacher D. Optimal management of cervical cancer in HIV positive patients: a systematic review. Cancer Med. 2015;4(9):1381-1393. doi:10.1002/cam4.485

8. Getahun T, Kaba M, Derseh BT. Intention to screen for cervical cancer in debre berhan town, amhara regional state, ethiopia: application of theory of planned behavior. $J$ Cancer Epidemiol. 2020;2020:3024578. doi:10.1155/2020/3024578

9. Ameya G, Yerakly F. Characteristics of cervical disease among symptomatic women with histopathological sample at Hawassa University referral hospital, Southern Ethiopia. BMC Women's Health. 2017;17(1):91. doi:10.1186/s12905-017-0444-5

10. Getahun F, Mazengia F, Abuhay M, Birhanu Z. Comprehensive knowledge about cervical cancer is low among women in Northwest Ethiopia. BMC Cancer. 2013;13(1):2. doi:10.1186/1471-2407-13-2

11. Gebru Z, Gerbaba M, Dirar A. Utilization of cervical carcinoma screening service and associated factors among currently married women in Arba Minch Town, Southern Ethiopia. J Women's Health Care. 2016;5 (297):2167-0420.1000297. doi:10.4172/2167-0420.1000297

12. Belete N, Tsige Y, Mellie H. Willingness and acceptability of cervical cancer screening among women living with HIV/AIDS in Addis Ababa, Ethiopia: a cross sectional study. Gynecologic Oncol Res Practice. 2015;2(1):6. doi:10.1186/s40661-015-0012-3 
13. Aweke YH, Ayanto SY, Ersado TL. Knowledge, attitude and practice for cervical cancer prevention and control among women of childbearing age in Hossana Town, Hadiya zone, Southern Ethiopia: community-based cross-sectional study. PLoS One. 2017;12(7): e0181415. doi:10.1371/journal.pone.0181415

14. Society AC. Guideline For the Prevention and Early Detection of Cervical Cancer.2018; Available from: https://WWW.Cancer.org/can cer/cervical-cancer/detection-diagnosis-staging/cervical-cancerscreening-guidelines.html.

15. WHO Guidelines for screening and treatment of precancerous lesions for cervical cancer prevention. 2013. 58 p.

16. Asseffa NA. Cervical cancer: ethiopia's outlook. J Gynecol Womens Health. 2017;5(2):555660. doi:10.19080/JGWH.2017.05.555660

17. Twinomujuni C, Nuwaha F, Babirye JN. Understanding the Low level of cervical cancer screening in Masaka Uganda using the ASE model: a community-based survey. PLoS One. 2015;10(6):e0128498. doi:10.1371/journal.pone.0128498

18. Ljnwo AA. utilization of cervical cancer screening in Sub Sahara Africa: a systematic review. Eur J Cancer Care. 2017.

19. Glanz K, Rimer BK, Viswanath K. Health Behavior and Health Education: Theory, Research, and Practice. John Wiley \& Sons; 2008.

20. Ajzen I. Theory of planned behaviour questionnaire. Measurement Instrument Database Social Science. 2013;2-9.

21. Francis J, Eccles MP, Johnston M, et al. Constructing questionnaires based on the theory of planned behaviour: A manual for health services researchers. Centre Health Services Research. 2004. University of Newcastle upon Tyne.

22. Ajzen I. Constructing a Theory of Planned Behavior Questionnaire. Amherst, MA: University of Massachusetts; 2006.

23. Kress CM, Sharling L, Owen-Smith AA, Desalegn D, Blumberg HM, Goedken J. Knowledge, attitudes, and practices regarding cervical cancer and screening among Ethiopian health care workers. Int J Women's Health. 2015;7:765.
24. Kumari K, Yadav S. Linear regression analysis study. J Practice Cardiovascular Sci. 2018;4(1):33. doi:10.4103/jpcs.jpcs_8_18

25. Verbeek M. Using linear regression to establish empirical relationships. IZA World Labor. 2017. doi:10.15185/izawol.336

26. Roncancio AM, Ward KK, Sanchez IA, et al. Using the theory of planned behavior to understand cervical cancer screening among Latinas. Health Education Behavior. 2015;42(5):621-626. doi:10.11 77/1090198115571364

27. Abamecha F, Tena A, Kiros G. Psychographic predictors of intention to use cervical cancer screening services among women attending maternal and child health services in Southern Ethiopia: the theory of planned behavior (TPB) perspective. BMC Public Health. 2019;19 (1):434. doi:10.1186/s12889-019-6745-x

28. Wollancho W, Amdissa D, Bamboro S, Wasihun Y, Tareke KG, Gizaw AT. Determining behavioral intention and its predictors towards cervical cancer screening among women in Gomma district, Jimma, Ethiopia: application of the theory of planned behavior. PLoS One. 2020;15(11):e0238472. doi:10.1371/journal.pone.0238472

29. Ogilvie GS, Smith LW, van Niekerk DJ, et al. Women's intentions to receive cervical cancer screening with primary human papillomavirus testing. Int j Cancer. 2013;133(12):2934-2943.

30. Sha-Mohammadi Z, Jalilian F, Mirzaei-Alavijeh M, et al. Intention and behavioral stages in pap testing: a cross-sectional study among kermanshah women's, the west of Iran. J Biol Today's World. 2014;3 (1):11-14

31. Chirayil EI, Thompson CL, Burney S. Predicting human papilloma virus vaccination and pap smear screening intentions among young singaporean women using the theory of planned behavior. Sage Open. 2014;4(4):2158244014554961. doi:10.1177/215824401455 4961

\section{Publish your work in this journal}

The International Journal of Women's Health is an international, peerreviewed open-access journal publishing original research, reports, editorials, reviews and commentaries on all aspects of women's healthcare including gynecology, obstetrics, and breast cancer. The manuscript management system is completely online and includes a very quick and fair peer-review system, which is all easy to use. Visit http://www.dovepress.com/testimonials.php to read real quotes from published authors. 